Research Article

\title{
Evaluation of anticonvulsant activity of volatile oil extract of Nigella sativa seeds by chemically induced seizure model in albino rats
}

\author{
Asmatanzeem Bepari ${ }^{1}$, Parashivamurthy B. M. ${ }^{2}$, Shaik Kalimulla Niazi ${ }^{3}$
}

\begin{abstract}
${ }^{1}$ Assistant Professor, Department of Pharmacology, Vijayanagara Institute of Medical sciences, Ballari, Karnataka, India

${ }^{2}$ Professor and HOD,

Department of Pharmacology, Mysore Medical College and Research Institute, Mysore, Karnataka, India

${ }^{3}$ Associate Professor, Department of Biochemistry, Riyadh Colleges of Dentistry and Pharmacy, Riyadh, Kingdom of Saudi Arabia
\end{abstract}

Received: 15 June 2016 Accepted: 29 June 2016

*Correspondence to: Dr. Asmatanzeem Bepari, Email: asmatanzu04 @ gmail.com

Copyright: (C) the author(s), publisher and licensee Medip Academy. This is an openaccess article distributed under the terms of the Creative Commons Attribution NonCommercial License, which permits unrestricted noncommercial use, distribution, and reproduction in any medium, provided the original work is properly cited.

\begin{abstract}
Background: The current therapeutic treatment of epilepsy with modern antiepileptic drugs is associated with side effects, dose related chronic toxicity, teratogenic effects and approximately $30 \%$ of the patients have intractable seizures. Natural products from folk remedies have contributed significantly in the discovery of modern drugs with novel structures and better safety and efficacy profiles. In this regard, one such plant is Nigella sativa. Objectives of the study was to evaluate the anticonvulsant activity of volatile oil extract of Nigella sativa seeds by pentylenetetrazole induced seizure model of epilepsy in albino rats and to evaluate the influence of volatile oil extract of Nigella sativa seeds on the anticonvulsant activity of sodium valproate in albino rats.

Methods: Male Albino rats (150-200 gms) were randomly selected, from central animal facility, Mysore Medical College and Research Institute, Mysore. The anticonvulsant activity was screened using pentylenetetrazole model. Albino rats were divided into 6 groups of 6 rats each. 6 groups were treated with gum acacia $0.5 \mathrm{ml}$ (control group), sodium valproate $300 \mathrm{mg} / \mathrm{kg}$ (standard group), groups 3, 4, 5 were administered the test drug, volatile oil extract of Nigella sativa seeds at doses of $200 \mathrm{mg} / \mathrm{kg}, 400 \mathrm{mg} / \mathrm{kg}$ and $600 \mathrm{mg} / \mathrm{kg}$ and group 6 was treated with the combination of test drug, volatile oil extract of $\mathrm{N}$. sativa seeds $200 \mathrm{mg} / \mathrm{kg}$ and sodium valproate $150 \mathrm{mg} / \mathrm{kg}$. All the drugs were dissolved in gum acacia and administered intraperitoneally $30 \mathrm{~min}$ prior to induction of seizures.

Results: The volatile oil of $N$. sativa seeds showed anticonvulsant activity at the dose of $400 \mathrm{mg} / \mathrm{kg}$ and $600 \mathrm{mg} / \mathrm{kg}$ body weight and the potentiation of anticonvulsant activity of sodium valproate. The anticonvulsant activity of volatile oil of $N$. sativa seeds was less when compared to sodium valproate.

Conclusions: The $N$. sativa seeds showed anticonvulsant activity in pentylenetetrazole induced seizure model of epilepsy. This study showed that volatile oil of $N$. sativa seeds potentiated the effect of sodium valproate.
\end{abstract}

Keywords: Epilepsy, Nigella sativa seeds, Volatile oil, Pentylene tetrazole, Sodium valproate, Seizure latency

\section{INTRODUCTION}

Epilepsy is one of the most common neurologic disorders of the brain, affecting at least 50 million people worldwide. It is the most common serious primary disease of the brain, accounting for $1 \%$ of the global burden of disease and knows no age, racial, social class, geographic, or national boundaries. ${ }^{1}$ The estimated incidence rate ranges from 40-60 per $1,000,000$ population/year. ${ }^{2}$ Approximately $5 \%$ of the general population experience at least one seizure, excluding febrile seizures. ${ }^{3}$ 
An epileptic seizure has been defined as a paroxysmal discharge of cerebral neurons accompanied by clinical phenomena apparent to the patient or to an observer. The phenomena can be motor, sensory or autonomic and there may also be impairment or complete loss of consciousness. Motor disturbances may include convulsions- which are involuntary, violent and spasmodic or prolonged contraction of skeletal muscles. ${ }^{4}$

Epilepsy is a condition, in which a person has recurrent seizures due to chronic, underlying process, implying that a person with single seizure or recurrent seizures due to correctable or avoidable circumstances does not necessarily have epilepsy. ${ }^{4}$

Epileptic disorders have been treated for thousands of years with variety of herbs. Potassium bromide was the first single compound in 1850, which was used for the treatment of epilepsy. Phenobarbital was the second compound discovered for the first clinical use in the treatment of epilepsy. ${ }^{5}$

Phenytoin was the first antiepileptic drug discovered using an animal seizure model. Trimethadione, the first treatment specifically for absence seizures was licensed in the 1940s, following laboratory evaluation with the pentylenetetrazole animal seizure model. ${ }^{5}$

Despite the introduction of several new therapeutic options in the 1990s, a significant fraction of the patients with epilepsy continue to live with uncontrolled seizure. There is still a need for an ideal antiepileptic agent with properties like broad spectrum activity, rapid onset of action, least side effects, good oral bioavailability and low cost. ${ }^{6}$

The WHO estimated that approximately $80 \%$ patients with epilepsy live in developing countries and most of them do not get adequate medical treatment. ${ }^{2}$ The current therapeutic treatment of epilepsy with modern antiepileptic drugs is associated with side effects, dose related chronic toxicity, teratogenic effects and approximately $30 \%$ of the patients have "intractable seizures" that do not respond to even the best available treatment. ${ }^{2,7}$

Natural products from folk remedies have contributed significantly in the discovery of modern drugs. Such products can be alternative source for the discovery of antiepileptic drugs with novel structures and better safety and efficacy profiles. Various phytochemical and pharmacological studies have been carried out on these antiepileptic plants. Thus, it is necessary to investigate for an antiepileptic agent that is highly efficacious as well as safe in terms of drug related toxicity. The aim of treating with an antiepileptic drug is not only to abolish the occurrence of seizures but also to lead a self-sustained life. Hence, search continues to develop newer more effective and safer neuroprotective agents for treatment of epilepsy. ${ }^{7}$
Since 1980, the World Health Organization has been encouraging countries to identify and exploit traditional medicine and phytotherapy. As per WHO, about $80 \%$ of the population in the world rely on the traditional medicine for the treatment of various diseases, including epilepsy. Therefore, the evaluation of rich heritage of traditional medicine is essential. In this regard, one such plant is N. sativa. ${ }^{8}$

N. sativa is vegetal specie of the Ranunculaceae family, commonly known as "black cumin seed", "neguilla" or "ajemuz", that is widely cultivated in the Mediterranean region. Its seeds have played an important role over the years in ancient Islamic system of herbal medicine and in Spain, where they have been traditionally used in folk medicine. ${ }^{9}$ Among Muslims, it is considered as one of the greatest healing medicine available, as it was mentioned in one of the Prophetic Hadith that the black seed is the remedy for all diseases except death. ${ }^{10}$

$N$. sativa plant is one of the most extensively studied, both phytochemically and pharmacologically. ${ }^{11}$ Black seed's constituents, in particular its major constituent thymoquinone, have recently shown antiepileptic effects in mice. ${ }^{12}$ Literature has indicated that the whole oil from black seeds is effective against PTZ-induced kindling in mice. Some other studies have pointed out that the treatment of mice with thymoquinone reduced the duration of myoclonic seizures and effectively protected the mice from mortality. ${ }^{12}$

Also, the extracts of $N$. sativa seeds have been used by patients to suppress coughs, disintegrate renal calculi, retard the carcinogenic process, treat abdominal pain, diarrhoea, flatulence, exert choleretic and uricosuric activities, anti-inflammatory and antioxidant effects. Besides, the essential oil was shown to have antihelminthic, antinematodal, antischistosomal, antimicrobial and antiviral effects. In addition, the crude oil prepared from the seeds produce a variety of pharmacological actions such as antihistaminic, diuretic and antihypertensive, hypoglycemic, antioxytocic, antinociceptive, respiratory stimulation, hematological protective, hepatoprotective and immunopotentiating effects. The latter pharmacological properties appear to be involved in the beneficial effects of $N$. sativa oil on headache, flatulence, blood homeostasis abnormalities, rheumatism and related inflammatory diseases. Moreover, the seeds are believed to have carminative, stimulatory and diaphoretic properties and are used in the treatment of bronchial asthma and eczema. ${ }^{11}$

In this study we have evaluated the antiepileptic activity of $N$. sativa seeds and compared with the standard sodium valproate in chemically induced seizures. We have also evaluated the influence of volatile oil of $N$. sativa seeds on sodium valproate. 


\section{Aims and objectives}

1. To evaluate the anticonvulsant activity of volatile oil extract of $N$. sativa seeds in albino rats.

2. To evaluate the influence of volatile oil extract of $N$. sativa seeds on the anticonvulsant activity of sodium valproate in albino rats.

\section{METHODS}

The study was conducted after the Instituitional Animal Ethics Committee clearance.

\section{Materials}

\section{Chemicals}

- Sodium valproate was obtained from Sun pharmaceuticals. Dose used was $300 \mathrm{mg} / \mathrm{kg}$ and was given intraperitoneally. ${ }^{13}$ Vehicle used was $5 \%$ gum acacia.

- Pentylenetetrazole was obtained from Sigma Aldrich. It was dissolved in distilled water and given at the dose of $80 \mathrm{mg} / \mathrm{kg}$ body weight intraperitonially. ${ }^{14}$

- Gum acacia: 5\%

- Distilled water

- Volatile oil of Nigella sativa (200 mg/kg, $400 \mathrm{mg} / \mathrm{kg}$ and $600 \mathrm{mg} / \mathrm{kg}$ body weight $)^{12}$

\section{Collection of seeds}

The seeds of $N$. sativa were obtained from a local market in Mysore, Karnataka state and authenticated by Department of Studies in Botany, University of Mysore, Manasagangotri, Mysore. The seeds were crushed and grounded into a fine powder. The powdered sample was stored in clean and dry container until used.

\section{Extraction of the volatile oil ${ }^{15}$}

The Steam distillation method was employed in the extraction process. $250 \mathrm{ml}$ of distilled water was added to $50 \mathrm{~g}$ of finely powdered sample placed in a distillation flask connected to a steam distiller, condenser and a receiver and was hydro distilled for four hours. The distillate was collected in coated glass bottles. Diethyl ether was added to separate the water phase. Anhydrous sodium sulphate was added to the supernatant fraction with simple agitation to dry volatile oil and then filtered. The filtrate was concentrated by distilling off the solvent in a rotary evaporator. The final residue of volatile oil was stored at $4{ }^{\circ} \mathrm{C}$ in coated glass bottles.

\section{Animals}

Thirty six adult healthy male albino rats of wistar strain of similar characteristics weighing 150-200 gms were selected from the central animal facility, Mysore Medical
College and Research Institute, Mysore and divided into 6 groups of six each.

All the test animals were allowed food and water ad libitum both being withdrawn just prior to experimentation. The test animals were subjected to further study after a gap of 24 hours to avoid any possible "kindling" effect. The drug preparations were administered intraperitoneally as shown in the table 1 . To evaluate the influence of volatile oil of $N$. sativa seeds on sodium valproate, a combination of sub-anticonvulsive dose of volatile oil of $N$. sativa seeds and sodium valporate were studied and results obtained were compared with anticonvulsive dose of sodium valproate alone. After an interval of 30 minutes pentylenetetrazole (PTZ) $\quad 80 \mathrm{mg} / \mathrm{kg}$ body weight was injected intraperitoneally. The duration of different parameters were noted.

Table 1: Drug preparations administered.

\begin{tabular}{|ll|}
\hline Group & Drugs administered \\
\hline I (Control group) & Gum acacia $0.25 \mathrm{ml} / 100 \mathrm{gm}$ \\
\hline II (Standard group) & Sodium valproate $300 \mathrm{mg} / \mathrm{kg}$ \\
\hline III (Test group-1; & Volatile oil extract of $N$. sativa \\
TGRP1) & seeds $200 \mathrm{mg} / \mathrm{kg}$ \\
\hline IV (Test group-2; & Volatile oil extract of $N$. sativa \\
TGRP2) & seeds $400 \mathrm{mg} / \mathrm{kg}$ \\
\hline V (Test group-3; & Volatile oil extract of $N$. sativa \\
TGRP3) & seeds $600 \mathrm{mg} / \mathrm{kg}$ \\
\hline VI (Test group-4; & $\begin{array}{l}\text { Sodium valproate } \\
\text { TGRP4) }\end{array}$ \\
& N. sativa seeds $200 \mathrm{mg} / \mathrm{kg}$ \\
\hline
\end{tabular}

\section{Pentylene tetrazole model}

The most valuable and commonly used model is the pentylenetetrazole (PTZ) model. Threshold PTZ seizures in rats $\&$ mice have long been considered as a model for absence attacks because of its selective therapeutic response to anti absence seizure drugs. This model is primarily a pharmacological prototype experiment, because the behaviour does not resemble the classical human 'absence seizure' but consists mainly of CLONIC seizures. All the anti-absence seizure drugs such as ethosuximide \& trimethadione, are more potent against PTZ rather than MES seizures, the exception being sodium valproate, which is active in both tests but more active in the PTZ test. Phenobarbital is active in the PTZ test, but is not useful in the clinical treatment of absence seizures. Experimental results suggest that the thalamus and to some extent, other brainstem regions, have an essential role on facilitating and inhibiting PTZ seizures. ${ }^{16}$

\section{Description}

The PTZ model evaluates the ability of potential antiepileptic agents to prevent CLONIC seizures and may 
correlate with activity against absence seizures. However, it is important to recall features of the human absence seizure which is characterised by an abrupt cessation of the patient's ongoing activity. ${ }^{17}$

Activity of a drug in this model may affect GABAergic brain systems, either by enhancing GABA levels or by altering sensitivity of postsynaptic GABA receptors. 18 Specific anti absence seizure drugs, such as ethosuximide \& trimethadione, which may act by blocking T-type voltage dependent $\mathrm{Ca}^{+2}$ channels, are also effective in the PTZ test. ${ }^{17}$

\section{Method}

In high doses PTZ acts on all parts of the CNS but the most sensitive region is the cerebral cortex, both tonic and clonic seizures are seen. Many variants of the PTZ test have been described in literature, including slow infusion through the tail vein to the end point of minimal seizures, a procedure often referred to as timed PTZ infusion approach. In this study, PTZ at a dose of 80 $\mathrm{mg} / \mathrm{kg}$ IP (dissolved in normal saline) was used, which produces excitement, myoclonic jerks, \& clonic seizures. An occasional fatal tonic seizure may occur. Seizures are produced in at least $97 \%$ of the animals. PTZ is given 30 minutes after the test drug. The PTZ response occurs about 5 to 10 minutes after administration. The rats are observed for half an hour after drug administration. The end points used by different researchers in the PTZ seizure model differ.

Prolongation of duration of seizure latency was taken as an index of protection and indicates efficacy of anticonvulsant activity of the test compound. ${ }^{18}$

The parameters studied in PTZ methods were:

1. Seizure latency (time taken for onset of seizure)

2. Myoclonic Jerk

3. Clonus

\section{Statistical analysis}

Analysis of normal distribution using Shapiro-Wilks normality test. As seizure latency is an independent variable for the assessing the anticonvulsant activity, direct univariate ANOVA followed by post hoc test for comparison between groups was calculated. For all the tests a 'P' value of 0.05 or less was considered for statistical significance. In the present study Fisher's LSD test was used for post-hoc comparison.

\section{RESULTS}

In this study the anticonvulsant activity of volatile oil of $N$. sativa seeds was evaluated against PTZ induced convulsions. The present study demonstrates an increase in the seizure latency, suggesting that the drug possess anticonvulsant property.

The results of the experiment are tabulated in Tables 2- 8, Figure 1-4. The results were analyzed statistically and tests of significance were found out.

Table 2: Sub group normality assumption checkShapiro-Wilks normality tests results.

\begin{tabular}{|llll|}
\hline Drugs & Statistic test & Seizure latency & Clonus latency \\
\hline \multirow{2}{*}{ Control } & SW statistic & 0.922 & 0.981 \\
\cline { 2 - 4 } & SW P-value & 0.522 & 0.956 \\
\hline \multirow{2}{*}{ Standard } & SW statistic & 0.982 & - \\
\cline { 2 - 4 } & SW P-value & 0.963 & - \\
\hline \multirow{2}{*}{ TG1 } & SW statistic & 0.941 & 0.936 \\
\cline { 2 - 4 } & SW P-value & 0.666 & 0.628 \\
\hline \multirow{2}{*}{ TG2 } & SW statistic & 0.852 & 0.894 \\
\hline \multirow{2}{*}{ TG3 } & SW P-value & 0.164 & 0.337 \\
\hline \multirow{2}{*}{ TG4 } & SW statistic & 0.902 & 0.903 \\
\cline { 2 - 4 } & SW P-value & 0.386 & 0.389 \\
\cline { 2 - 4 } & SW statistic & 0.941 & - \\
\hline
\end{tabular}

Table 3: Univariate ANOVA.

\begin{tabular}{|c|c|c|c|c|c|c|}
\hline Phases of convulsion & & SS & df & MS & $\mathbf{F}$ & p-value \\
\hline \multirow{2}{*}{ Seizure latency } & Between groups & 307852.2 & 5 & 61570.44 & \multirow{2}{*}{24.131} & \multirow{2}{*}{$<0.0005 *$} \\
\hline & Error & 76545.33 & 30 & 2551.51 & & \\
\hline \multirow{2}{*}{ Clonus latency } & Between groups & 1004937.4 & 5 & 200987.4 & \multirow{2}{*}{124.74} & \multirow{2}{*}{$<0.0005^{\circ}$} \\
\hline & Error & 48336.16 & 30 & 1611.206 & & \\
\hline
\end{tabular}

*indicates statistically significant

Table 4: Comparison of seizure latency duration in seconds among various groups in pentylene tetrazole model.

\begin{tabular}{|llllllllll|}
\hline SI.No. of rats & $\mathbf{1}$ & $\mathbf{2}$ & $\mathbf{3}$ & $\mathbf{4}$ & $\mathbf{5}$ & $\mathbf{6}$ & Mean & SE \\
\hline Control group & 101 & 146 & 129 & 107 & 158 & 112 & 125.5 & 9.33 \\
\hline Standard group & 246 & 325 & 288 & 317 & 384 & 187 & 291.16 & 27.88 \\
\hline Test group 1 & 162 & 121 & 124 & 155 & 143 & 135 & 140.0 & 6.73 \\
\hline Test group 2 & 268 & 340 & 218 & 255 & 233 & 238 & 258.66 & 17.75 & 32.08 \\
\hline Test group 3 & 288 & 232 & 353 & 402 & 415 & 247 & 322.83 & 379.16 \\
\hline Test group 4 & 325 & 420 & 365 & 372 & 438 & 355 & & 17.22 \\
\hline
\end{tabular}


Table 5: Seizure latency matrix of pairwise comparison probabilities.

\begin{tabular}{|lllllll|}
\hline & CT & STD & TG1 & TG2 & TG3 & TG4 \\
\hline CT & 1.000 & & & & & \\
\hline STD & $<0.0005^{*}$ & 1.000 & & & & \\
\hline TG1 & 0.623 & $<0.0005^{*}$ & 1.000 & & & \\
\hline TG2 & $<0.0005^{*}$ & 0.274 & $<0.0005^{*}$ & 1.000 & \\
\hline TG3 & $<0.0005^{*}$ & 0.286 & $<0.0005^{*}$ & $0.036^{*}$ & 1.000 & \\
\hline TG4 & $<0.0005^{*}$ & 0.005 & $<0.0005^{*}$ & $<0.0005^{*}$ & 0.063 & 1.000 \\
\hline
\end{tabular}

*indicates statistically significant

Table 6: Comparison of clonus latency in seconds among various groups in pentylene tetrazole model.

\begin{tabular}{|lllllllll|}
\hline Sl.No. of rats & $\mathbf{1}$ & $\mathbf{2}$ & $\mathbf{3}$ & $\mathbf{4}$ & $\mathbf{5}$ & $\mathbf{6}$ & $\mathbf{M e a n}$ & SE \\
\hline Control group & 166 & 212 & 195 & 192 & 232 & 183 & 196.66 & 9.37 \\
\hline Standard group & - & - & - & - & - & - & - & - \\
\hline Test group 1 & 255 & 208 & 183 & 217 & 210 & 247 & 220 & 10.91 \\
\hline Test group 2 & 352 & 297 & 411 & 465 & 473 & 309 & 384.5 & 31.32 \\
\hline Test group 3 & 461 & 387 & 424 & 475 & 480 & 357 & 430.66 & 20.57 \\
\hline Test group 4 & - & - & - & - & - & - & - & \\
\hline
\end{tabular}

Table 7: Clonus latency matrix of pairwise comparison probabilities.

\begin{tabular}{|lllllll|}
\hline & CT & STD & TG5 & TG6 & TG7 & TG8 \\
\hline CT & 1.000 & & & & & \\
\hline STD & $0.000^{*}$ & 1.000 & & & & \\
\hline TG1 & 0.322 & $<0.0005^{*}$ & 1.000 & & & \\
\hline TG2 & $<0.0005^{*}$ & $<0.0005^{*}$ & $<0.0005^{*}$ & 1.000 & & \\
\hline TG3 & $<0.0005^{*}$ & $<0.0005^{*}$ & $<0.0005^{*}$ & 0.056 & 1.000 & \\
\hline TG4 & $<0.0005^{*}$ & 1.000 & $<0.0005^{*}$ & $<0.0005^{*}$ & $<0.0005^{*}$ & 1.000 \\
\hline
\end{tabular}

*indicates statistically significant

Table 1 provides the SW value and p-value for seizure latency and clonus latency in PTZ model across different treatment groups. All follow normal distribution

Table 4 represents the Post hoc Fisher's test and p-values for seizure latency and are tabulated in the respective cells. It is seen that TG1 is insignificant to control group. It is observed from the table that Test group 2 and test group 3 is significant with respect to Control group however is insignificant with Standard group. It is also seen that TG4 is significantly better than standard. Also TG3 is insignificant with respect to TG4.

Table 8: Percentage protection in seizure latency among various treatment groups in pentylenetetrazole model.

\begin{tabular}{|ll|}
\hline Treatment groups & Percentage protection \\
\hline Standard group & $100 \%$ \\
\hline Test group 1 & $48.08 \%$ \\
\hline Test group 2 & $88.83 \%$ \\
\hline Test group 3 & $110.87 \%$ \\
\hline Test group 4 & $130.22 \%$ \\
\hline
\end{tabular}

Table 6 represents the Post hoc Fisher's test and p-values for clonus and are tabulated in the respective cells. It is observed from the table that test group 2, test group 3and test group 4 is significant with respect to Control group, but test group 4 is insignificant or comparable to standard.

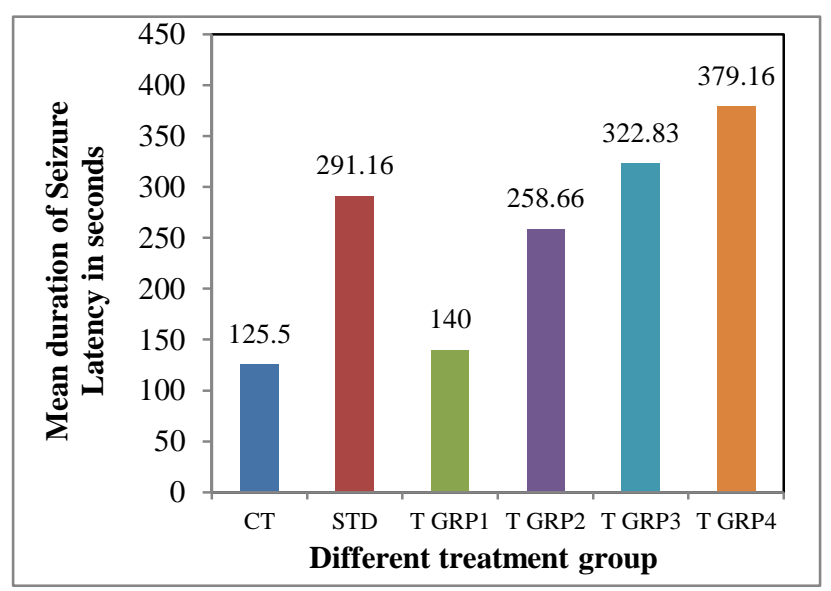

Figure 1: Comparison of mean duration of seizure latency across different treatment groups. 


\section{Least Squares Means}

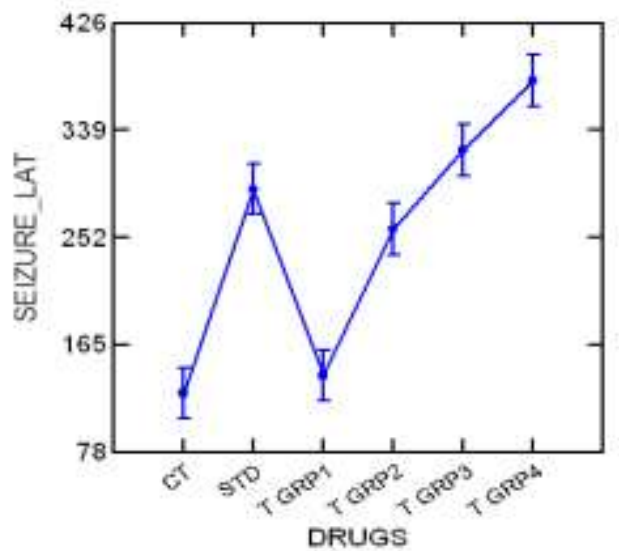

Figure 2: comparison of least square means of seizure latency.

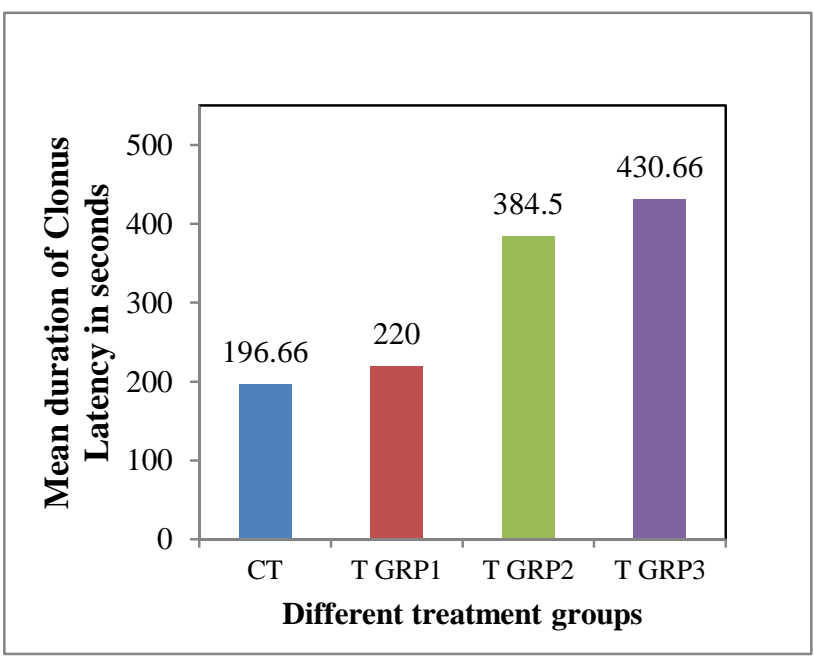

Figure 3: Comparison of mean duration of clonus latency across different treatment groups.

\section{Least Squares Means}

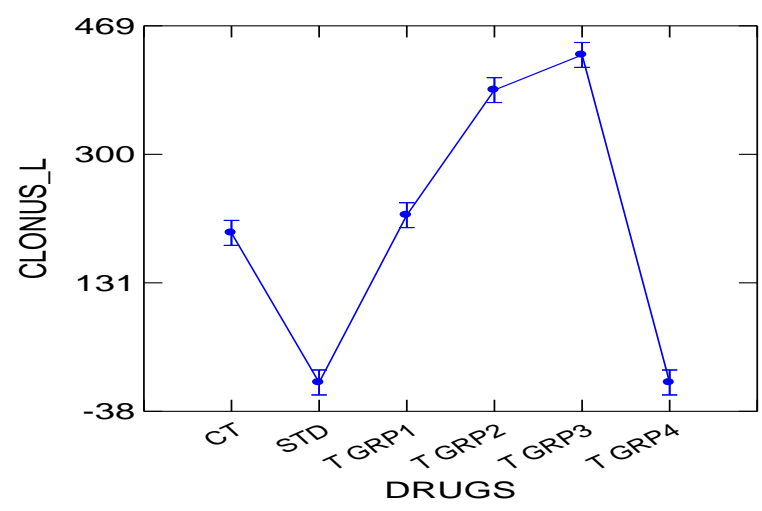

Figure 4: Comparison of least square means of clonus.

\section{DISCUSSION}

Almost $30 \%$ of epileptic patients suffer from pharmacoresistance, which is associated with social isolation, dependent behaviour, low marriage rates, unemployment, psychological issues and reduced quality of life. The treatment of pharmacoresistant patients usually requires polytherapy. Currently available antiepileptic drugs have a limited efficacy, and their negative properties limit their use and cause difficulties in patient management. The long term use of antiepileptic drugs is limited due to their adverse effects, withdrawal symptoms, deleterious interactions with other drugs and economic burden, especially in developing countries. 3,20

There is still a need for an ideal antiepileptic agent with properties like broad spectrum activity, rapid onset of action, least side effects, good oral bioavailability and low cost. $^{6}$ Natural products from folk remedies have contributed significantly in the discovery of modern drugs and can be alternative source for the discovery of antiepileptic drugs with novel structures and better safety and efficacy profiles. Hence, search should continue to develop newer more effective and safer neuroprotective agents for treatment of epilepsy. ${ }^{7}$

This study showed that $N$. sativa seeds have anticonvulsant activity.

Dose 1-200 mg/kg body weight

Analysis of results of TGRP1 animals in Pentylenetetrazole (PTZ) model (Table 4-7 \& Figure 1-4) showed an increase in duration of seizure latency and increase in clonus latency which were statistically not significant, when compared to control group. All animals exhibited clonus.

\section{Dose 2-400 mg/kg body weight}

Analysis of results of TGRP2 animals in PTZ model (Table 4-7 \& Figure 1-4) showed an increase in duration of seizure latency and clonus latency. The increase in seizure latency was statistically significant when compared to control group and statistically insignificant to standard group, thus comparable to standard. The increase in duration of clonus latency was statistically significant when compared to control group but not comparable to standard group. All animals exhibited clonus.

\section{Dose 3-600 mg/kg body weight}

Analysis of results of TGRP3 group animals in PTZ model (Table 4-7 \& Figure 1-4) showed an increase in duration of seizure latency and clonus latency. The increase in seizure latency was statistically significant when compared to control group and statistically insignificant to standard group, thus comparable to standard. The increase in duration of clonus latency was 
statistically significant when compared to control group but not comparable to standard group. All animals exhibited clonus.

Dose 4-Volatile oil of $\mathrm{N}$. sativa $200 \mathrm{mg} / \mathrm{kg}+$ Sodium valproate $150 \mathrm{mg} / \mathrm{kg}$ body weight

Analysis of results of $6^{\text {th }}$ group animals (table $4-7 \& 1,2$ bar diagram and 1,2 line diagram ) showed increase in duration of seizure latency, which was statistically significant and more than the standard group. Also the increase in duration of seizure latency was statistically insignificant and comparable to group $5^{\text {th }}$. There was complete abolition of clonus in all 6 animals in this group.

The prolongation of seizure latency was taken as protective end point. $^{21}$

At doses of $200 \mathrm{mg} / \mathrm{kg}$ of volatile oil of $N$. sativa seeds, there was no significant anticonvulsant activity, whereas at $400 \mathrm{mg} / \mathrm{kg}$ and $600 \mathrm{mg} / \mathrm{kg}$ there was significant anticonvulsant activity.

Percentage protection offered by sodium valproate was $100 \%$ against seizure latency. The percentage protection of volatile oil of $N$. sativa seeds at the doses of $200 \mathrm{mg} / \mathrm{kg}, 400 \mathrm{mg} / \mathrm{kg}$ and $600 \mathrm{mg} / \mathrm{kg}$ were $48.08 \%$, $88.83 \%$ and $110.87 \%$ respectively (Table 8 ). The percentage protection offered by combination volatile oil of $N$. sativa seeds $200 \mathrm{mg} / \mathrm{kg}$ with sodium valproate $150 \mathrm{mg} / \mathrm{kg}$ was $130.22 \%$ against seizure latency. This indicates that the anticonvulsant activity of volatile oil of $N$. sativa seeds is comparable to the standard drug, sodium valproate. The anticonvulsant activity of volatile oil of $N$. sativa $200 \mathrm{mg} / \mathrm{kg}$ with sodium valproate $150 \mathrm{mg} / \mathrm{kg}$ is comparable and more significant when compared to standard drug alone.

The above analysis reveals that,

- Volatile oil extract of Nigella sativa seeds by itself has significant anticonvulsant activity at the dose of $400 \mathrm{mg} / \mathrm{kg}$ and $600 \mathrm{mg} / \mathrm{kg}$ body weight. The anticonvulsant activity produced at $600 \mathrm{mg} / \mathrm{kg}$ is comparable to standard drug sodium valproate at dose of $300 \mathrm{mg} / \mathrm{kg}$.

- The combination of volatile oil extract of Nigella sativa seeds with sodium valproate at their subanticonvulsant doses showed significant anticonvulsant activity, comparable to and more significant when compared to standard drug alone. This suggests that volatile oil extract of Nigella sativa seeds has potentiated the effect of sodium valproate, may be better than standard drug alone.

- Hence, the test compound may be useful in absence seizures (petit mal epilepsy). Also the addition of volatile oil extract of Nigella sativa seeds to subanticonvulsive doses of sodium valproate has superior efficacy in absence seizures. Hence, standard drug, sodium valproate can be used at low doses to attain the same therapeutic benefit when used with combination of volatile oil extract of Nigella sativa seeds, thus minimizing the adverse effects of sodium valproate which is used chronically in the management of epilepsy. However, further studies are required to confirm the same.

\section{ACKNOWLEDGEMENTS}

Authors would like to thank Dr. Hema N.G., Professor and Dr. Basavanna P.L., Professor, Department of Pharmacology, Mysore Medical College and Research Institute, Mysore, for their precious and timely suggestions and advice. Authors would like to Dr. N. Vadiraja, Assistant Professor, Department of Community Medicine, Mysore Medical College and Research Institute, Mysore for carrying out the statistical analysis the study.

\section{Funding: No funding sources}

Conflict of interest: None declared

Ethical approval: The study was approved by the Institutional Ethics Committee

\section{REFERENCES}

1. Mostafa RM, Moustafa YM, Mirghani Z. Thymoquinone alone or in combination with phenobarbital reduces the seizure score and the oxidative burden in pentylenetetrazole-kindled rats. Oxid Antioxid Med Sci. 2012;1(3):185-92.

2. Deshmukh RS, Chaware VJ, Biyani KR. Alpha lipoic acid potentiates the antiseizure activity of Gabapentin in mice. Intern J Res Pharm Biomed Sci. 2012;3(3):1004-7.

3. Wahab A. Difficulties in treatment and management of epilepsy and challenges in new drug development. Pharmaceut. 2010;3:2090-110.

4. Daniel H. Lowenstein. Seizures and epilepsy. Harrisons principles of internal medicine. 17th ed. Mc Graw; 2009:2498-2513.

5. Pathak S, Singh L, Singh T, Sharma SK. Recent development in anti-epileptic drugs. Intern $\mathbf{J}$ Pharmaceut Biol Sci. 2013;1(1):50-60.

6. Panchaksharimath P, Singh S, Devaru S. Study on the anticonvulsant activity of Pentazocine in albino rats. J Chem Pharm Res. 2011;3(5):468-72.

7. Atigari DV, Gundamaraju R, Sabbithi S, Chaitanya KB, Ramesh C. Evaluation of antiepileptic activity of methanolic extract of Celastrus paniculatus Wild. Whole Plant in Rodents. Int J Pharm Phytopharmacol Res. 2012;2(1):20-5.

8. Paarakh PM. Nigella sativa Linn: a comprehensive review. Indian J Natural Prod Resour. 2010;1(4):409-29.

9. El-Naggar T, Gomez-Serranillos MP, Palomino OM, Arce C, Carretero ME. Nigella sativa $L$ seed extract 
modulates the neurotransmitter amino acids release in cultured neurons in vitro. J Biomed Biotech. 2010;2010:1-8.

10. Ahmad A, Husain A, Mujeeb M, Khan SA, Najmi AK, Siddique NA, et al. A review on therapeutic potential of Nigella sativa: a miracle herb. Asian Pacific J Trop Biomed. 2013;3(5):337-52.

11. Gali-Muhtasib H, el-Najjar N, Schneider-stock R. The medicinal potential of black seed (Nigella sativa) and its components. Lead Molecules From Natural Products. 2006;1:133-53.

12. Raza M, Alghasham AA, Alorainy MS, El-Hadiyah TM. Potentiation of valproate-induced anticonvulsant response by nigella sativa seed constituents: the role of GABA receptors. Intern J Health Sci. 2008;2(1):15-25.

13. Malhotra J, Seth SD, Gupta SK, Gupta YK. Adenosinergic mechanisms in anticonvulsant action of diazepam and sodium valproate. Environ Toxicol Pharmacol. 1996 Jul 15; 1(4): 269-77.

14. Husniye Birman, Kadriye Akgun Dar, Aysegul Kapucu, Samet Acar, Gulay Uzum. Effects of Luteolin on liver, kidney and brain in pentylenetetrazol- induced seizures: Involvement of
Metaloproteinases and NOS activities. Balkan Med J 2012; 29: 188-96

15. Kacem R, Meraihi Z. Effects of essential oil extracted from Nigella sativa (L.) seeds and its main components on human neutrophil elastase activity. Yakugaku Zasshi 2006; 126: 301-305

16. Godman LS, Toman JEP, Swinyard EA. Comparison of maximal seizures evoked by PTZ \& electroshock in mice \& their modification by anticonvulsant. J Pharm Pharmacol. 1953:168-76.

17. Rogawski MA, Porter RJ. Antiepileptic drugs: pharmacological mechanisms \& clinical efficacy with consideration of promising developmental stage compounds. Pharmacol Rev. 1990;42(3):223-86.

18. Rooney S, Ryan MF. Effects of alpha-hederin and thymoquinone, constituents of Nigella sativa, on human cancer cell lines. Anticancer Res. 2005;25:2199.

19. Vogel HG. Drug Discovery and Evaluation: Pharmacological Assays. New york Springer; 2008; 3rd Ed; E.2.2.1, Pentylenetetrazole induced convulsions: 613 .

Cite this article as: Bepari A, Parashivamurthy BM, Niazi SK. Evaluation of anticonvulsant activity of volatile oil extract of Nigella sativa seeds by chemically induced seizure model in albino rats. Int J Basic Clin Pharmacol 2016;5:1300-7. 